E International

\title{
A Roadmap to Funding Infrastructure Development
}

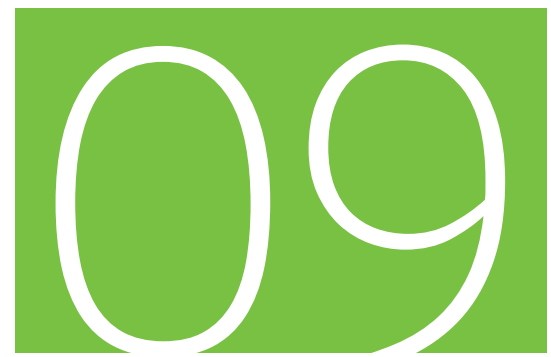

Discussion Paper 2012•09

Carlos Ugarte, Gabriel Gutierrez and Nick Phillips,

Cintra Infraestructuras, S.A., Spain 


\title{
A Roadmap to Funding Infrastructure Development
}

\author{
Discussion Paper No. 2012-9
}

Prepared for the Roundtable on:

Public Private Partnerships for Funding Transport Infrastructure:

Sources of Funding, Managing Risk and Optimism Bias

(27-28 September 2012)

\section{Carlos UGARTE, Gabriel GUTIERREZ}

and Nick PHILLIPS

Cintra Infraestructuras, S.A.

Spain

September 2012 


\section{INTERNATIONAL TRANSPORT FORUM}

The International Transport Forum at the OECD is an intergovernmental organisation with 54 member countries. It acts as a strategic think tank with the objective of helping shape the transport policy agenda on a global level and ensuring that it contributes to economic growth, environmental protection, social inclusion and the preservation of human life and well-being. The International Transport Forum organizes an annual summit of Ministers along with leading representatives from industry, civil society and academia.

The International Transport Forum was created under a Declaration issued by the Council of Ministers of the ECMT (European Conference of Ministers of Transport) at its Ministerial Session in May 2006 under the legal authority of the Protocol of the ECMT, signed in Brussels on 17 October 1953 , and legal instruments of the OECD.

The Members of the Forum are: Albania, Armenia, Australia, Austria, Azerbaijan, Belarus, Belgium, Bosnia-Herzegovina, Bulgaria, Canada, Chile, China, Croatia, the Czech Republic, Denmark, Estonia, Finland, France, FYROM, Georgia, Germany, Greece, Hungary, Iceland, India, Ireland, Italy, Japan, Korea, Latvia, Liechtenstein, Lithuania, Luxembourg, Malta, Mexico, Moldova, Montenegro, Netherlands, New Zealand, Norway, Poland, Portugal, Romania, Russia, Serbia, Slovakia, Slovenia, Spain, Sweden, Switzerland, Turkey, Ukraine, the United Kingdom and the United States.

The International Transport Forum's Research Centre gathers statistics and conducts co-operative research programmes addressing all modes of transport. Its findings are widely disseminated and support policymaking in Member countries as well as contributing to the annual summit.

\section{Discussion Papers}

The International Transport Forum's Discussion Paper Series makes economic research, commissioned or carried out at its Research Centre, available to researchers and practitioners. The aim is to contribute to the understanding of the transport sector and to provide inputs to transport policy design. The Discussion Papers are not edited by the International Transport Forum and they reflect the authors' opinions alone.

The Discussion Papers can be downloaded from:

\section{www.internationaltransportforum.org/jtrc/DiscussionPapers/jtrcpapers.html}

The International Transport Forum's website is at: www.internationaltransportforum.org

For further information on the Discussion Papers and other JTRC activities, please email:

\section{itf.contact@oecd.org}

This document and any map included herein are without prejudice to the status of or sovereignty over any territory, to the delimitation of international frontiers and boundaries and to the name of any territory, city or area. 


\section{TABLE OF CONTENTS}

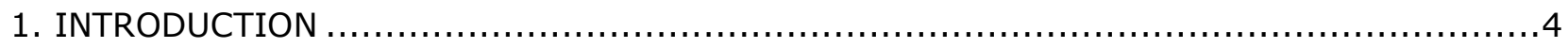

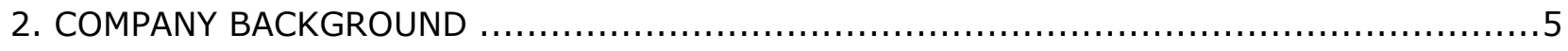

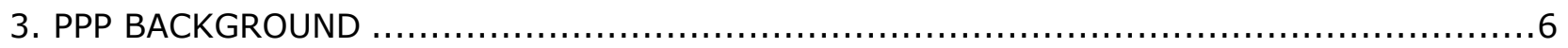

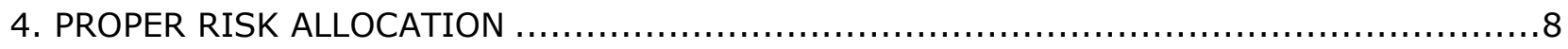

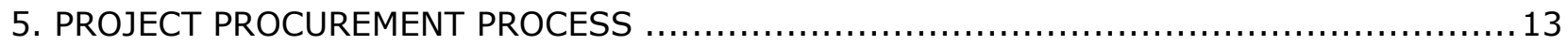

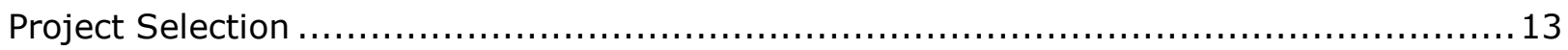

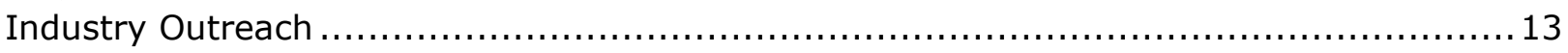

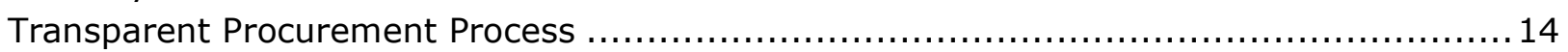

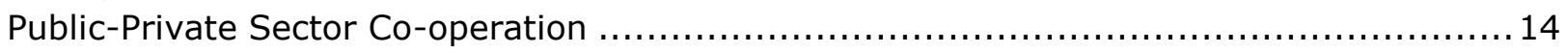

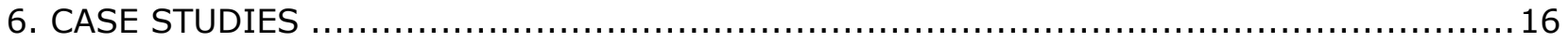

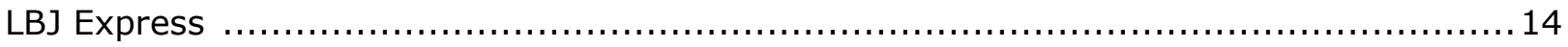

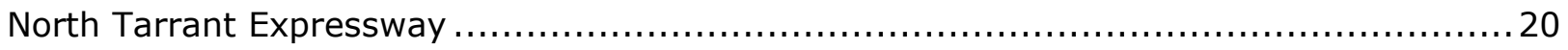

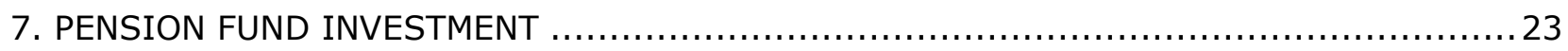




\section{INTRODUCTION}

This paper discusses the initiatives and procedures necessary for the successful development of large-scale transportation PPP projects from a developer's point of view. The topics covered in this paper include:

- Project Procurement

- Proper Risk Allocation

- Direct Investments by Pension Funds, et al.

4 Carlos Ugarte, Gabriel Gutierrez and Nick Phillips-Discussion Paper 2012-9 - @ OECD/ITF, 2012 


\section{COMPANY BACKGROUND}

Cintra is one of the largest private developers of transport infrastructure in the world. We currently manage a portfolio of 21 road concessions across Spain, Canada, the USA, Portugal, Ireland and Greece, representing a total managed investment of approximately $\$ 25$ billion. These projects include the world's first all-electronic, barrier free toll highway, the multi award-winning 108km 407 Express Toll Route in Canada and the Chicago Skyway, a 99 year lease agreement covering the first privatization of an existing toll road in the US. More recently, Cintra was awarded, and has begun construction on, two managed lanes projects in the Dallas-Fort Worth area, the LBJ Express and the North Tarrant Express.

As an infrastructure developer and long-term investor, Cintra is fully involved in the delivery and operations of all its toll roads. Cintra invests equity into all its projects, operates and maintains all assets using in-house resources, and exercises close supervision and control during the delivery stage, to ensure each project is well constructed and fit for its purpose.

Cintra has a proven track record in facing and solving challenging road concession projects through combining technical excellence with a flexible approach to project finance, leading to the delivery of new and upgraded infrastructure around the globe. Cintra has a strong reputation for rigorous and effective risk management, implemented through bespoke contracts, tailored to each project. As a result of our close collaboration with our sister company Ferrovial Agromán, which undertakes civil engineering construction works, Cintra provides a comprehensive approach to project development, investment, construction, operations and maintenance.

Backing Cintra is its parent company, the Ferrovial Group, based in Spain and one of the world's leading infrastructure companies, with activities in construction, management, maintenance and services, a market capitalization of $\$ 8.9$ billion, revenues over $\$ 9.4$ billion, and a workforce of over 60,000 people. Ferrovial Group's portfolio and track record includes management of key assets such as London's Heathrow Airport and construction of the world's 3rd largest desalination plant in Spain. 


\section{PPP BACKGROUND}

Public-Private Partnerships (PPPs) have recently emerged as an increasingly popular way for governments around the world to develop large-scale infrastructure projects. This rapid growth has been spurred through the continued expansion of burgeoning infrastructure needs in the face of ever-tightening budgetary constraints in both developed and developing countries. Under this duress, governments are seeking alternative ways to improve infrastructure while maintaining some semblance of fiscal responsibility. And, as a result, PPPs have emerged as a popular solution because when properly structured, they allow:

- Proper (Efficient) Risk Allocation

- Value for Money via increased competition

- Ability to leverage limited public funds

- Capped liability exposure

- Other:

\begin{tabular}{l} 
Greenfield projects \\
\hline Fast development time = savings in cost escalation. \\
Streamlined construction process (turnkey contracts, fixed prices) \\
$\begin{array}{l}\text { New assets generate public sector revenue with no gov't investment or future } \\
\text { obligations } \\
\text { Customer-orientation, ownership mentality: maintenance, quality, technologies }\end{array}$
\end{tabular}

Available:

Not available

Partially available

There are many different kinds of Public-Private Partnerships with varying levels of private sector involvement. However, the most common, and the type that will be the focus of this paper, is known as a Design-Build-Finance-Operate-Maintain ("DBFOM") transaction. Under a DBFOM, the government grants a private sector partner the right to develop a new piece of public infrastructure. The private partner takes on full responsibility and risk for delivery and operation of the public project against pre-determined performance standards established by the government. The private-sector partner is compensated through the revenue stream generated by the project, which could take the form of a user charge (such as a highway toll) or, in some cases, an annual government payment for performance (often called a "shadow toll" or "availability charge").

6 Carlos Ugarte, Gabriel Gutierrez and Nick Phillips- Discussion Paper 2012-9 - (C) OECD/ITF, 2012 
Shadow tolls are schemes where payments made by the State to the private Concessionaire are calculated on a per vehicle basis. On the contrary, availability payments are payments made by the State in exchange for a level of service, and the payment is made regardless of the level of traffic.

\section{PPP Drivers}

Over the past decade, there have been many examples of positive and negative PPP projects and procurements throughout the world. Cintra's experience as both a market participant and observer has given the company valuable insight into what is necessary to procure and develop successful PPP projects now and in the future. From this experience, we believe that the two main drivers of successful PPP project development are the Proper Risk Allocation and the Project Procurement Process. 


\section{PROPER RISK ALLOCATION}

The goal of a PPP is to increase project value through the minimization of risk. Risk minimization occurs by assigning compartmentalized areas of risk to that party which is best able to mitigate the potential harmful effects that may stem from improper management of that risk. With the understanding that these parties, usually a private and a public sector partner, have inherent strengths and weaknesses that are often complimentary, a risk sharing structure may be established to assign risk to that party best able to mitigate that risk. However, to take full advantage of this concept, the industry had to undergo a complete shift in how they structured their infrastructure delivery deals.

In the past, under the "traditional" method, public infrastructure projects were completed for the procuring agency via separate, independent contracts with design/engineering firms and construction firms. This bifurcated process was designed to avoid collusion and fraudulent claims, but also eliminated the opportunity for synergy between these two interrelated functions of design and construction. This lack of direct communication between designers and contractors often created problems, which delayed completion schedules and drove up costs. Further, many areas of risk stayed with the Public Sector (as detailed in the chart below). This retained risk, if not properly managed, increased contingencies and lowered the project value.

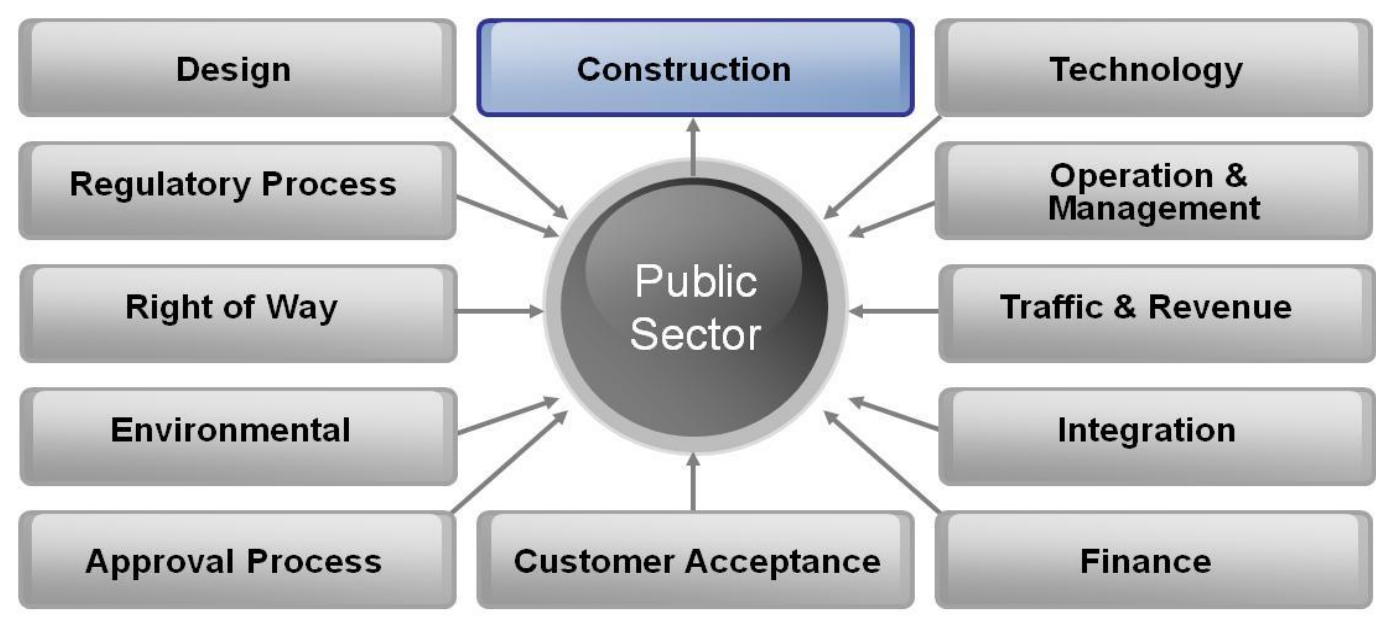

\section{Misaligned interests between contractor and Public Sector}

8 Carlos Ugarte, Gabriel Gutierrez and Nick Phillips- Discussion Paper 2012-9 - (C) OECD/ITF, 2012 
However, with the shift towards PPPs, public agencies are provided the opportunity to allocate more risk away from the public sector and towards the private developer. Under this deal structure, there are not bifurcated contracts. Instead, PPPs feature a single, more expansive, contract (often known as a "concession" agreement) agreed to between the private and public partners. This contracting structure facilitates risk transfer and more responsibility can be placed on the private sector under the umbrella of this concession agreement. Now, instead of contracting with a designer, and then in turn with a constructor, the procuring agency can sign a single concession agreement with a consortium of entities that will provide designer, constructor, financier, operator and maintenance services. In doing so, this contracting structure effectively shifts the risk of these additional services to the Private Sector. The chart below illustrates a potential risk allocation for the development of a PPP tollroad.

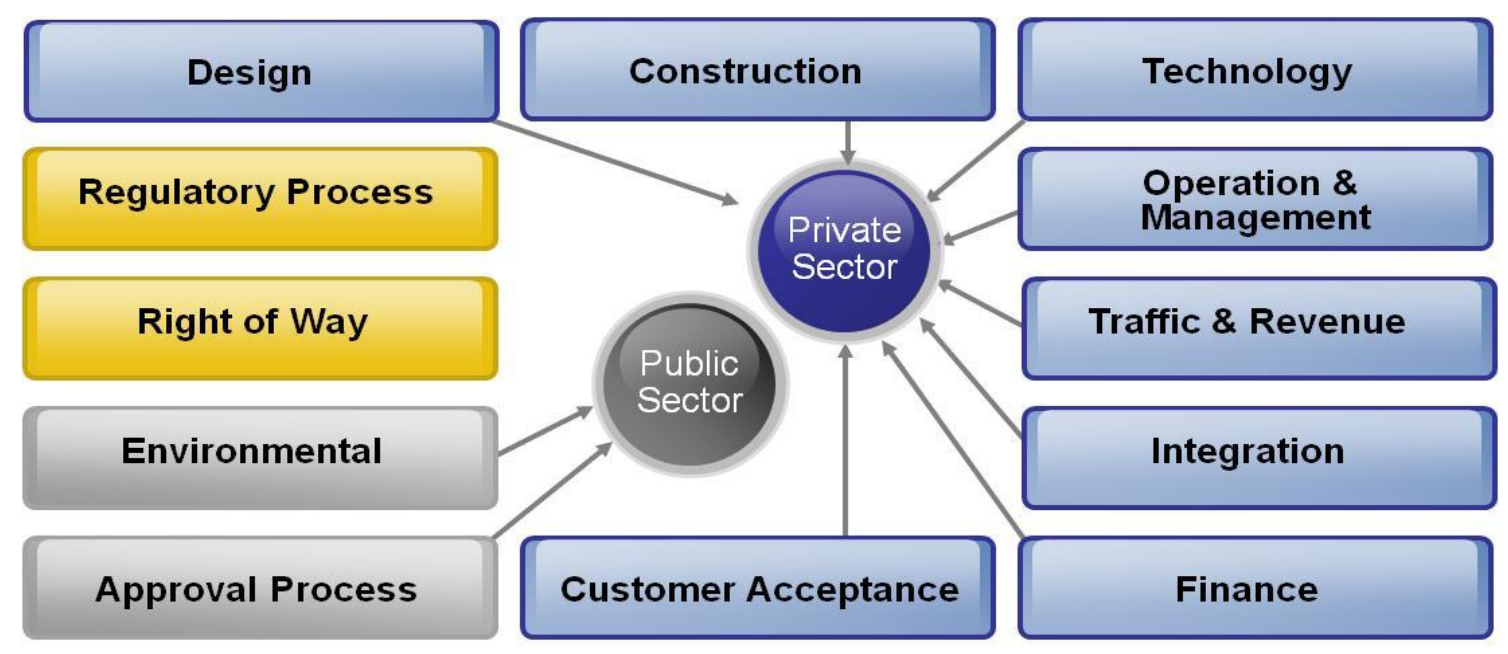

Shared Public Private

From the above chart, we see what risks are usually shifted to the Private Sector. While these shifted risks may vary from project to project, they are all based in the idea of allocating risk to that party best able to mitigate it. For example, a private developer with significant experience operating and maintaining toll road assets will probably be better positioned to operate and maintain a toll road project than a public partner that does not count a single toll road among its current inventory. On the other hand, the Private Sector could shoulder the risk of environmental approval. However, the cost of that burden would be significantly higher than if that risk was borne by the public sector, who often works with partnering governments and retains the environmental expertise specific to their particular geographic location. The efficient allocation of these risks, along with all the others, reduces uncertainty, thus increasing the project's viability and the value received by the public sector. 
Demand Risk vs. Availability Payments

Deal structures are often defined based on the allocation of demand risk. If asset users pay for the privilege of using that asset, the private sector can be compensated directly by the user or the revenue can go to the government who will then compensate the developer through set payments (Availability payments). The advantage to taking this risk comes from the belief that the asset will be used by the public at or above projected use, in which case the "upside" will go to that party that holds the demand risk. Conversely, the disadvantage to taking this risk would come if projections are not met and there is not enough revenue produced by the asset to compensate the project's financial expectations.

Since the onset of the global financial crisis, it has been stated that the private sector is unwilling to take demand risk and thus it needs to remain with the public sector. However, this assertion is untrue. Cintra believes that the private sector is better positioned to understand and project this risk, and thus mitigate the risk of asset use that falls below projections. Therefore, for the public sector to retain this risk, the risk is misallocated and erodes the project value. Some of the benefits of a demand risk project include:

\section{Reduced Public Sector Liability}

Availability payment structures are essentially Design-Build contracts with an additional long-term funding liability from the public sector to the private sector. Given the lack of operational risk for the private sector, it is not as motivated to look for ways to optimize the project's viability.

Conversely, demand risk projects shift long-term risk from the public to the private sector and, as a result, the private side is extremely motivated to find all possible efficiencies. These efficiencies can be passed on to the public sector via reduced or eliminated one-time upfront subsidies.

For example, in the LBJ project in Dallas, the public sector had allocated $\$ 700$ million in public funds for the project. As a result of the project structure and Cintra's ability to develop efficiencies in the project's development and operations, the required subsidy was only $\$ 489$ million, a $\$ 211$ million savings for the state. Most savings are obtained by rescoping the project, rather than by fine-tuning the operational expenses.

\section{A Reality Check}

The single most important reason for allocating demand risk to the private sector is so that the private sector can act as a reasonability and feasibility check for government agencies. Large-scale infrastructure projects are complex developments that involve large construction and capital costs, that account for the greatest share of the potential savings of the project - including operational efficiencies - and can be huge liabilities if proper project selection and scoping are not undertaken. By allocating demand risk to the private sector, the public sector eliminates the risk of overestimating or underestimating project scope. The economic viability and necessity of the project receives a rigorous reality check by the developers, and by extension their lenders, as they are risking their own capital.

10 Carlos Ugarte, Gabriel Gutierrez and Nick Phillips-Discussion Paper 2012-9 - (c) OECD/ITF, 2012 
This feedback significantly reduces the risk that projects are over built or under built, harming their optimal value production. The long-term investment profile of the developer aligns the goals of the infrastructure project with the goals of the capital behind it thus adding efficiency to the development process.

There have been many examples of the pitfalls for purely public financing decisions in recent history. For instance, in a project that included expansion of Japanese high speed rail services to non-profitable markets essentially bankrupted the public rail company despite the incredible success of the main Shinkansen trunk line. The private sector could have served as a realistic advisor to argue against this unwise investment.

\section{Equity: Availability Payments Minimize the Developer's Role}

The revenue profile of an availability payment based project often mitigates the true potential added value of involving private infrastructure operators and developers. These projects are not awarded on the basis of operational expertise or ability to forecast and manage future demand but rather on commodity-based construction pricing. As a result, the main proponents and bidders in large-scale availability payment structures are third-party consultants and larger construction and financing consortiums. Developers involved in these projects are only occasionally required to contribute equity, and usually only a token amount, which leads to a much smaller risk profile being assumed by the developer/operator and implies less use of their services and knowledge.

As such, this bidding profile features parties (the financing and construction companies) that have a much shorter investment horizon and, much as with Design-Build projects, are looking to win the project on the basis of a narrow range of specifications rather than by proposing to enhance value through innovative engineering or optimized capital structuring. Without real equity repayment risk, projects are typically designed to maximize short term profits at the expense of improving design, engineering or lifecycle costs. Then, once the construction milestone payments are received, these parties will usually look to flip their participation to a third-party, placing project responsibilities with entities that were not vetted by the government agency during the procurement process.

Moving into operations, an availability payment structure dis-incentivizes the developer from directing resources to optimizing asset use. Under an availability mechanism, the road operator will meet minimal contract standards or face penalties; however, he will have no reason to go above these standards as his payment will remain constant. In fact, with more users, the developer may see an increase in operations and maintenance costs, cutting into his margin. Under a scenario where the developer is actively seeking to expand useage, he will maximize asset services to encourage use, thus pushing the asset to serve as many users as possible. This second scenario aligns developer and government goals and incentivizes the private sector throughout the life of the concession to provide top quality services. 


\section{Demand Risk Stimulates Private Sector Innovation}

In addition to enhancing goal alignment by matching the long-term nature of infrastructure development with long-term investment horizons, true infrastructure developers also invest larger equity commitments to their projects (as a percentage of total cost). As a result, these developers remain constantly vigilant in seeking creative ways to improve project feasibility.

Many proponents of availability payment financing argue that the tight spreads that typically separate final bids indicate that approach increases competition. However, it is more likely that the opposite is actually true. When three world-class construction companies are provided with the same specifications for a project, they will likely have similar prices as the largest cost driver is raw materials. The only tangible differences will be the risk premium (i.e. margin). It is for this reason that construction bids on availability payment projects are often within a few percentage points of one another.

The true value of PPP projects is in the ingenuity and creativity that can be brought in from the private sector. To protect their significant investment, developers typically perform intense due diligence to develop an understanding of a project's dynamics. Often, this understanding is better than that of third-party advisors or construction companies whose motivation is not fully based on developing infrastructure efficiently but rather on items such as success fees or gaining further patronage.

The due diligence of the developer can have significant effects on project value. For instance, one of the main areas where these traits can be monetized is with value engineering. As further elaborated upon in the LBJ case study below, Cintra was able to reduce the capital costs of the project by $\$ 970$ million by developing an innovative alternative design that accomplished the same end goals of the original project specification.

Another area of potential innovative value creation lies in project phasing and scoping as developers looking to maximize long term returns will look to develop the most efficient project lifecycle and development plan. As further explained in the LBJ/NTE case studies, both of those projects had initial scopes that were economically unfeasible. However, feedback provided by the private sector allowed for the successful development of both projects. 


\section{PROJECT PROCUREMENT PROCESS}

There are four elements during the project procurement phase that are vital to the success of any PPP development:

- Project Selection

- Industry Outreach

- Transparent Procurement Process

- Public-Private Sector Co-operation

While there are other elements that are important during the procurement, the items listed above are vital and if any are lacking, the project will not succeed.

\section{Project Selection}

During the height of the PPP boom in the mid-2000s, there was a significant amount of capital chasing relatively few projects. As a result, certain projects were identified that, were not ideal candidates for PPP development. Many of these projects were roads whose necessity was based on optimistic future growth forecasts or so-called "pet projects" that were politically savvy but not financially viable. As a result, there are many road projects today that have entered bankruptcy proceedings or are facing significant financial stress.

The primary lesson learned from this period is that PPP development is only viable for projects that are designed to resolve a tangible problem hindering the efficiency of a city or region's infrastructure. PPPs do not work economically as engines to spur growth. Rather, they must be constructed in response to establish need, or in the face of imminent growth.

Some jurisdictions have emerged from the PPP boom with a sense that demand-risk projects are not feasible in the post-financial crisis environment. However, this is not the case. One need look no further than the two US case studies attached to see evidence of successfully financed transportation infrastructure projects with full-demand risk transfer.

\section{Industry Outreach}

It is beneficial for any procuring agency to involve all stakeholders, including potential sponsors and investors, during the early development phase. By beginning this involvement early, potential problems can be addressed early, increasing the project's potential for success and value for the public sector. 
Potential bidders on the LBJ Express and North Tarrant Express were offered a variety of ways to express their opinions on both the development and structure of the procurement - a move that delivered significant improvements to the outcomes of both projects.

Unlike most Requests for Qualifications (RFQs), the procuring authority engaged potential bidders on the issues facing the project by requiring respondents to submit a Conceptual Development Plan, which accounted for $30 \%$ of the scoring. In this plan, respondents had to develop an initial plan for the project utilizing the resources that were available at the time, which included preliminary traffic studies and a conceptual design that were completed to the $30 \%$ level.

As a result of this early interaction, Cintra was able to come up with changes and alterations to the project scope and phasing that substantially improved the project's viability.

This interaction with developers continued throughout the process and secured the successful procurement of both projects.

\section{Transparent Procurement Process}

The technical and political objectives and priorities should be made clear from the outset of procurement, to give the private sector the opportunity to develop efficient solutions. These objectives could include minimum capacity added, maximum amounts of public funds, or required opening dates.

Furthermore, the limitations and parameters of the project need to be outlined as well.

This occurred on the LBJ Express project, where the Texas Department of Transportation outlined the project parameters, including the total public funds available. This set clear expectations and increased competition as it clearly identified the financial parameters. Despite some expectations to the contrary, the winning consortium, led by Cintra, did not use the maximum available subsidy - the LBJ Express was won with a public funding requirement of US\$445 million, despite US\$700 million being available.

\section{Public-Private Sector Co-operation}

While it is important for the procurement approach to have set objectives and priorities, the more flexible the procurement process can be, the more opportunities there will be for the private sector to develop more economically sustainable infrastructure, which requires lower contributions from public funds. 
One example is the submission of as Alternative Technical Concepts (ATCs) and Alternative Financial Concepts (AFCs) by the proposers. These are new ideas submitted by the proposers in confidence during the procurement process.

Following consideration, the proposals are either approved, allowing their inclusion in the bidder's final submission, or rejected. Usually, this procurement approach not only has the ability to improve project viability but also increases competition between bidders.

Bidders should be provided with a base reference design ( $30 \%$ Design) on projects but significant design flexibility should be permitted as value engineering is one of the main ways the private sector adds value to the project. 


\section{CASE STUDIES}

\section{CASE STUDY 1: IH-635 MANAGED LANES (LBJ EXPRESS) - DALLAS, TEXAS}

The IH-635 Managed Lanes (LBJ) project was the first DFW project to begin procurement, with an RFQ released in May 2005. The LBJ Express had been in various levels of planning since 1995 despite having support from all local stakeholders. An internal TxDOT memo from August 2002 estimated that project construction "could easily approach 20 years".

TxDOT declared the Cintra-led consortium's response to the RFQ to be the "best overall proposal" and commended Cintra's ability to identify concerns relating to issues such as the right-of-way acquisition and our ability to balance the needs and concerns of the public while completing the project development.

\section{Initial project scope:}

The initial scope included the addition of six managed tolled lanes along a $33.6 \mathrm{~km}$ segment of IH635. Additionally, the scope called for the reconstruction of the eight general-purpose toll-free lanes on IH-635.

TXDOT's construction cost estimate for total initial project scope was US $\$ 2.875$ bn (2004, including all segments under planning).

\section{Main objectives of the project:}

(i) Maximise value to the public sector

(ii) Congestion relief: average daily traffic

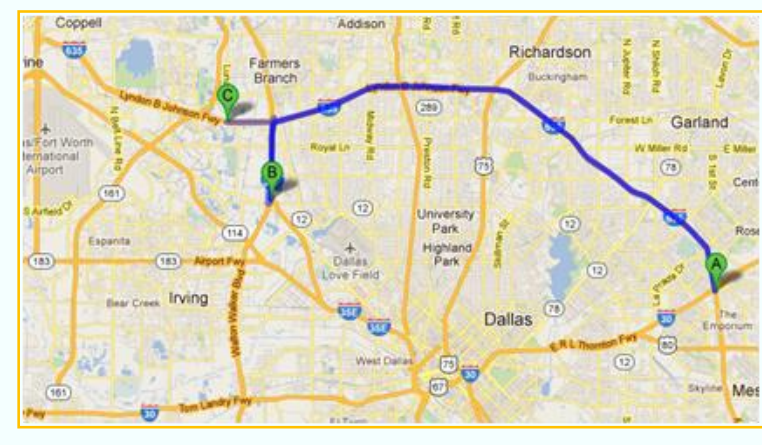
counts exceeded 240,000 vehicles.

(iii) Improved safety: the corridor needed wider lanes, additional shoulders, barrier separated traffic lanes and continuous service roads to help reduce accidents.

(iv) Improved air quality as a result of reduced levels of congestion and maintaining traffic flow on managed lanes

\section{Main challenge of the project:}

The existing traffic flows had to be maintained during construction. The high level of development along the corridor, the environmental constraints and public requirements constrained the development of the works. To overcome this, the original design included a twin bore tunnel, each bore containing three managed lanes, over an $8 \mathrm{~km}$ section of the IH-635 corridor, and elevated managed lanes along the I-35E portion. 


\section{WHAT IMPROVED THE PROJECT TECHNICAL SOLUTION?}

\section{Efficiencies in scoping}

The original scope of LBJ Express was not economically viable and this put the project's development in jeopardy. During the RFQ stage, there was collaborative work of the procuring authority, Cintra and other proponents, in a number of alterations to the scope which did not compromise achievement of the main project objectives. The alterations included:

Reduce the length of the project from the original $33.6 \mathrm{~km}$ to $21.9 \mathrm{~km}$ by removing a segment of road that did not have enough traffic congestion to warrant the addition of managed lanes on the corridor.
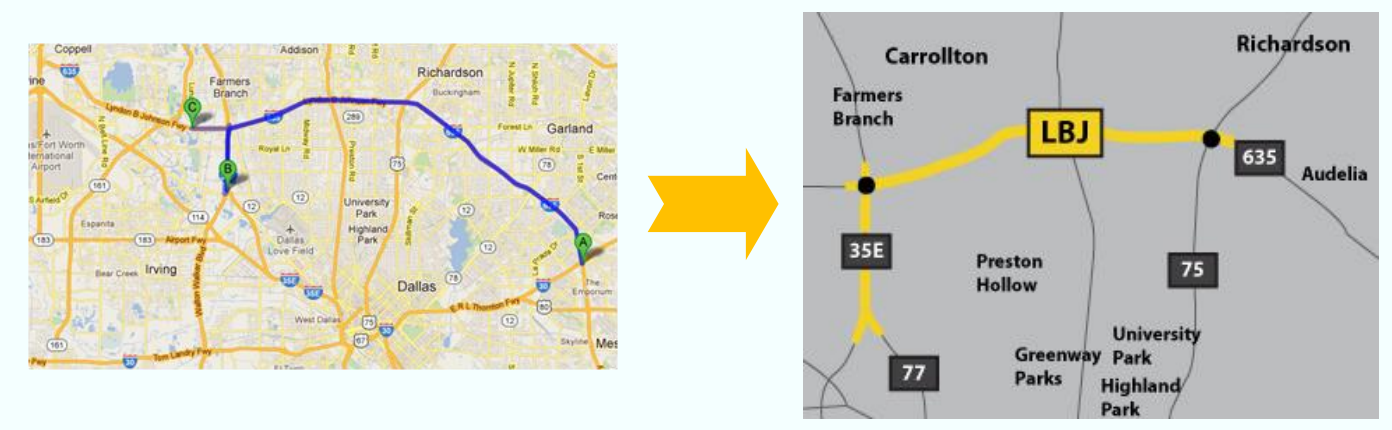

Open the project in sections rather than at completion of the entire project. This change would allow the developer to increase revenues during the initial stages of the project and reduce ramp-up periods as local commuters became accustomed to the managed lanes concept prior to full implementation.

\section{Alternative Technical Concepts}

During the procurement process, Cintra developed three ATCs to improve the connectivity of the IH635 managed lanes on the north-south routes and maximise the project's future revenues. The improvements would increase accessibility to the main freeways crossing the project and impact positively on revenue generation. The example illustrated in the diagram below had the potential to deliver a $7 \%$ to $10 \%$ increase in revenues for the first 15 years. 


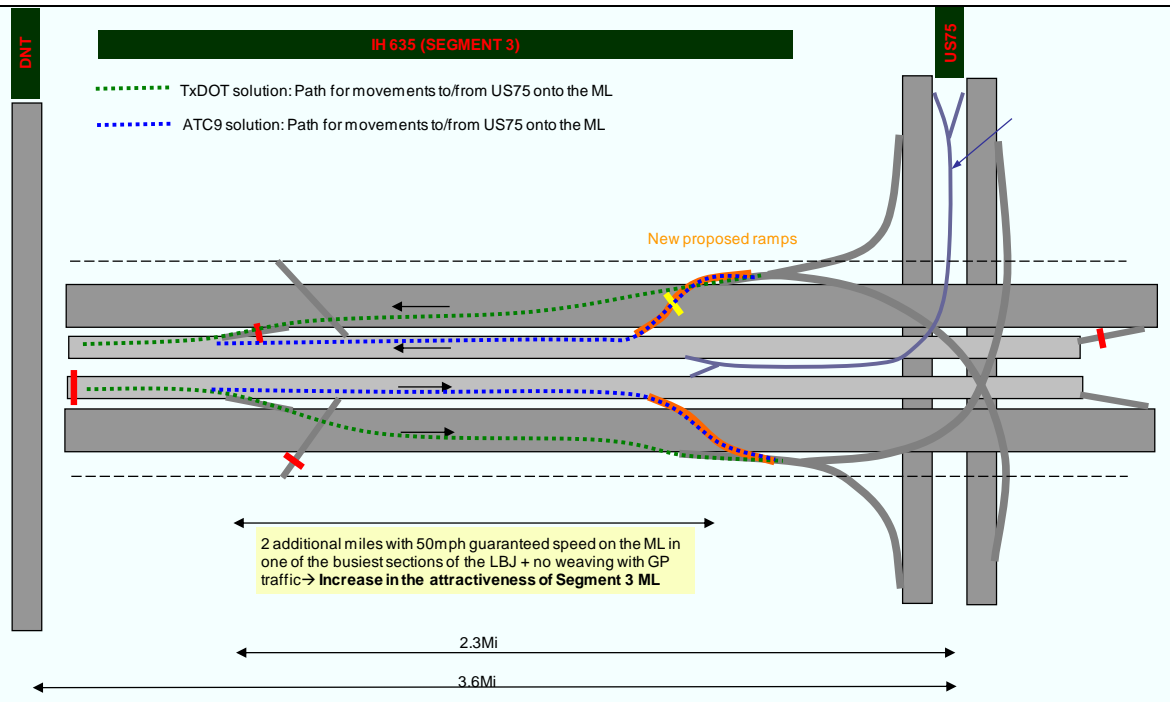

\section{Construction solutions:}

The LBJ Express is located in a densely developed corridor in Dallas, making cost-effective design solutions difficult as there was limited right-of-wayavailable. The design specifications for this project required six subsurface managed lanes to be constructed over a $3.2 \mathrm{~km}$ section in the middle of the corridor.

The original technical solution called for dual tunnels that would provide the three managed lanes in each direction plus shoulders to reduce traffic impact during construction on this heavily used section. This design concept significantly increased the cost of the project and threatened its viability. A typical section of one of the tunnels is shown below.

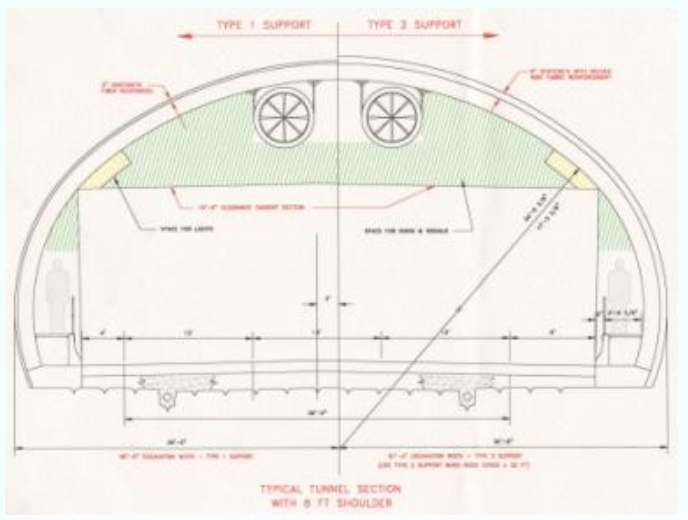

Cintra, in conjunction with our sister company and construction partner, FerrovialAgroman, presented a solution that completely eliminated the tunnels and made the best use of the available right-of-way. Not only did this comply with the traffic management restrictions, but it also resulted in Cintra's consortium reducing construction costs by US\$ 970 million if compared to the most competitive bid offering the tunnel solution. Cintra's solution also resulted in improved safety and reduced ongoing maintenance costs, maximising value for money beyond the concession period. 
C Cintra consortium

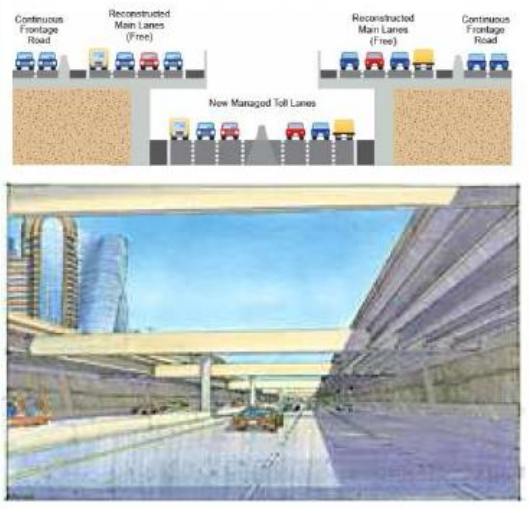

Construction Cost: $\$ 2,11$ Billion
Competing Consortium

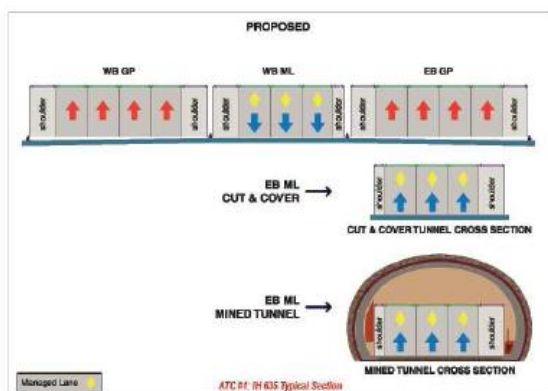

Construction Cost: $\$ 3,08$ Billion

Carlos Ugarte, Gabriel Gutierrez and Nick Phillips-Discussion Paper 2012-9 - @ OECD/ITF, 201219 


\section{CASE STUDY 2: NORTH TARRANT EXPRESS - FORT WORTH, TEXAS}

In December 2006, TxDOT released an RFQ for the North Tarrant Express (NTE) project. NTE comprised a network of related improvements to address critical transport and mobility issues in North Tarrant county, in Fort Worth region. The development of the project was crucial to reducing severe congestion and was an important part of TxDOT's wider transport planning efforts. TXDOT concluded that harnessing private-sector creativity through a concession and predevelopment agreement was the best way to ensure cost-effective and expedited delivery of the infrastructure.

\section{Initial scope:}

The initial scope for the NTE included improvements on six connected highway corridors including the addition of new general purpose lanes as well as the development of a four to six-lane managed lanes network throughout the corridor. The total length of all six segments was $58 \mathrm{~km}$.

TxDOT's construction cost estimate for total initial project scope was US $\$ 1,992$ (US $\$ 2006$, including all segments under planning).

\section{Main challenges of the project:}

The main challenges of the project were:

(i) Multiple segments with varying levels of predevelopment work completed. TXDOT required the entire network to be developed by one developer to reduce cost redundancies and enhance future funding.

(ii) Demanding traffic management requirements during construction required the contractor to keep traffic moving safely, with

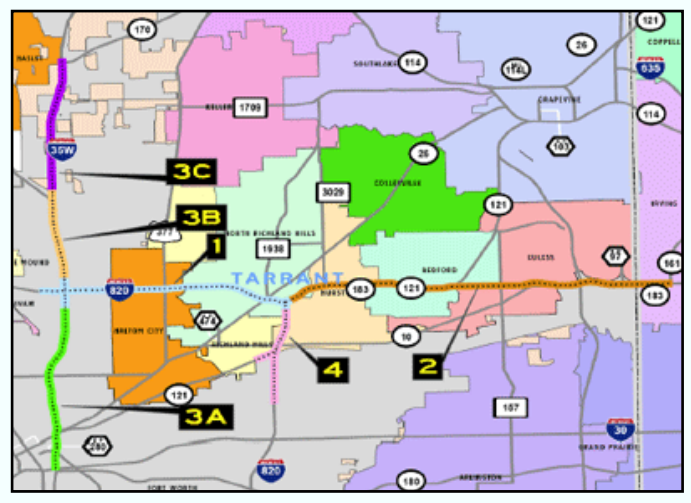
complex signalling.

\section{Main objectives of the project:}

(i) Maximise value to the public sector

(ii) Congestion relief

(iii) Almost double road capacity along the corridor

(iv) Address the requirements of continued population growth 


\section{WHAT IMPROVED THE PROJECT TECHNICAL SOLUTION?}

\section{Procurement environment}

TXDOT had concluded that an identified first phase of the project, Segment 1, with an approximate length of $10,24 \mathrm{~km}$ was ready for development through a concession. The other segments of the project were not ready for immediate development at that time, and TxDOT concluded that employing private sector creativity through predevelopment activities would bring efficiency

North Tarrant Express started as a two-part procurement process in which developers were to bid for Segment 1, with an option to a portion of Segment 2 and the rest of the project segments being part of a Pre-Development Agreement.

However, Segment 1 was not viable as a stand-alone project with its original configuration and neither Segment 2 nor the other identified segments improved the project's overall feasibility.

\section{Cintra's approach to segmentation}

Cintra's analysis showed that there were a number of ways in which the project delivery could be de-scoped and phased, and we proposed to TxDOT the sub-segmentation of sections of the project.

In the initial scope, Segment 1 included the complete reconstruction of the IH35W/SH183 interchange, the addition of 2 managed lanes in each direction and the addition of 1 general purpose lane in each direction. This would have increased the capacity of the segment from the 2 General Purpose Lanes (GPLs) in each direction to 3 GPLs and 2 managed Lanes in each direction, an increase of $150 \%$.

In order to increase the feasibility of the project Cintra proposed to split the Segment 1 scope into different components that would be delivered in stages:

The addition of 2 managed Lanes and 1 GPL by 2030, or before if a certain revenue threshold trigger was met

Reconstruction of the IH35W/SH183 interchange
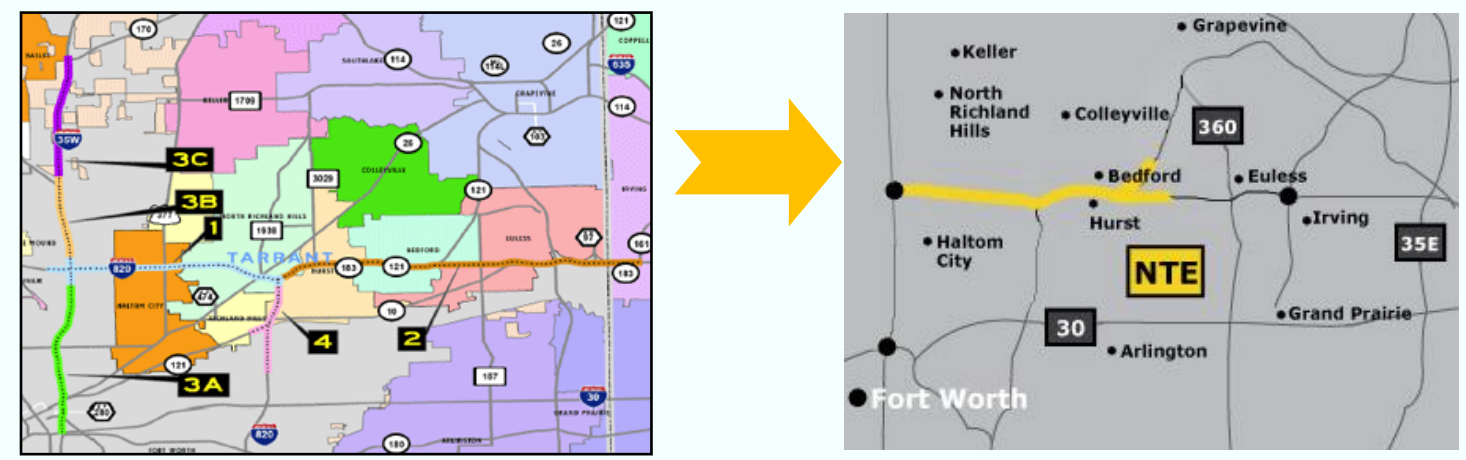
This segmentation process was captured in a procurement approach that defined a Mandatory Proposal Scope, which was the minimum scope for each bidder (addition of $2 \mathrm{ML}$ in Segment 1) and Additional Scope Segments whereby a Proposer may include one or more additional optional scope segments in their Proposal to the extent that those segments can be constructed within the maximum available public funding.

The Mandatory Proposal Scope plus the Additional Scope segments included in the Proposal became the Proposer's Proposed Scope. A scoring system was applied to award higher scores for proposals that maximize the public benefit by developing more segments within the maximum available funding constraints. That scoring criteria was then tied back into the general evaluation criteria. Under this plan, the Proposed Scope, as defined above, would be built at the beginning of the concession term. 


\section{PENSION FUND INVESTMENT}

Pension funds are a relatively new entrant into the world of infrastructure investment but their importance has grown considerably over the last decade with larger funds such as OMERS and OTPP becoming significant players in the industry.

The attraction of infrastructure investing for pension funds is three-fold. Infrastructure assets typically provide:

\section{- Long Term Duration}

Due to the high initial expenditures relating to developing infrastructure, concession terms are typically significantly lengthy with investment durations in the range of 30-50 years and as long as 99 years in some cases. These long-term return profiles match the long-term liabilities that pension funds naturally face thus reducing the fund's exposure to reinvestment risk.

\section{- Inflation Linked Returns}

Most concessions are linked to inflation via adjustments to user fees throughout the course of the concession that are linked to CPI or GDP growth. Additionally, the demand profiles of infrastructure users tend to be relatively inelastic to incremental changes in tolls.

\section{- $\quad$ Reduced Volatility and Increased Diversification}

Compared to equity investments, properly structured infrastructure investments have a relatively low volatility, particularly on more mature assets that have an established revenue history. Furthermore, infrastructure investments have a low correlation to at-large equity market returns.

Despite the multitude of benefits that infrastructure investment can provide to pension fund, the brief history of pension funds and infrastructure investments has been a mixed bag. For the largest and most sophisticated funds, infrastructure investment has become a core competency as they have the size and resources to develop and dedicate teams to the sector. This is borne out by a 2010 Infrastructure Investor ranking that showed eight of the largest 30 investors in the sector were pension funds.

However, for the remaining funds the road has not been as prosperous. Due to the niche characteristics of the sector, other funds have tried to invest in the sector through private-equity style infrastructure funds developed by investment banks and similar sponsors. 
According to a Preqin survey, 58\% of investors indicated their main concerns with infrastructure investing were related to the current format including concerns with high fees, fund structures and benchmarking. This style of fund is not appropriate for infrastructure investing as the high fees charged by the sponsors (typically a base percentage of funds committed plus a portion of returns above a IRR hurdle) eat away the more modest returns of infrastructure and can end up increasing volatility to pension funds. These style of funds have the potential to sour a large source of capital from investing in the sector.

For example in its bid for both the LBJ Express and the North Tarrant Express, Cintra partnered with the Dallas Police and Fire Pension Fund (DPFPF). DPFPF is the type of fund that would typically be limited only to PE-style funds if it desired to invest in infrastructure. Many of the risks presented by the projects were new to the fund and, similarly to other funds, its team of investment professionals was not familiar with the asset class as it did not have the resources to have a fully-dedicated team to a niche asset class. DPFPF had an interest in infrastructure but was not overly excited by the PE fund structure.

As a result, DPFPF ended up becoming the first US pension fund to make a direct investment in the construction and operations of a major toll road. The relationship continues still with DPFPF being an equity investor in the next Cintra-led project, the NTE Extension. 
